BULLETIN Bulletin hispanique

HISPANIQUE Université Michel de Montaigne Bordeaux

118-1 | 2016

La Guerre Civile espagnole aujourd'hui (1936-2016)

\title{
Guerra de memorias y memorias de la guerra
}

\section{Pilar Domínguez Prats}

\section{(2) OpenEdition}

\section{Journals}

Edición electrónica

URL: http://journals.openedition.org/bulletinhispanique/4218

DOI: 10.4000/bulletinhispanique.4218

ISSN: 1775-3821

\section{Editor}

Presses universitaires de Bordeaux

\section{Edición impresa}

Fecha de publicación: 15 julio 2016

Paginación: 65-80

ISBN: 979-10-300-0058-0

ISSN: 0007-4640

Referencia electrónica

Pilar Domínguez Prats, « Guerra de memorias y memorias de la guerra », Bulletin hispanique [En línea] 118-1 | 2016, Publicado el 15 julio 2019, consultado el 06 septiembre 2019. URL : http:// journals.openedition.org/bulletinhispanique/4218; DOI : 10.4000/bulletinhispanique.4218 


\title{
Guerra de memorias y memorias de la guerra
}

\author{
Pilar Domínguez Prats \\ Universidad de Las Palmas de Gran Canaria
}

L'article analyse des souvenirs de la guerre civile, à savoir les récits personnels écrits sous la forme d'autobiographies, de lettres ou de journaux de guerre publiés entre 2006 et 2014, source essentielle pour la construction d'une histoire sociale de cette période. Parmi les " ego-documents " publiés, sont d'abord analysés ceux des enfants et des femmes. Sont aussi commentés les souvenirs des acteurs du soulèvement et des républicains : combattants espagnols, Brigades internationales et exilés républicains.

Mots clés: mémoires, Guerre Civile espagnole, récits autobiographiques, études de genre, enfants de la guerre, exil républicain.

El artículo analiza las memorias de la guerra civil, es decir los relatos personales escritos en forma de autobiografías, cartas o diarios de guerra, publicados entre 2006 y 2014, fuente privilegiada para la construcción de una historia social de este periodo. Entre los «ego-documentos» publicados, se analizan en primer lugar los de los niños y las mujeres. A continuación se comentan algunas memorias de los actores del bando sublevado y del bando republicano : combatientes españoles, brigadistas internacionales y exiliados republicanos.

Palabras clave: memorias, Guerra Civil espańola, relatos autobiográficos, estudios de género, niños de la guerra, exilio republicano.

This article examines memoirs and diaries of the Spanish Civil War, published between 2006 and 2014, a privileged source for the construction of a social history of this period. Among the "ego - documents» published, we first analyse those of children and women. The article then deals with some memoirs from both pro-Franco and Republican sides, Spanish fighters, International Brigades and Republican exiles.

Keywords: memoirs, Spanish Civil War, personal narratives, gender, children of the war, republican exile. 
A partir del siglo XXI hemos asistido en España a un amplio proceso A tendente a favorecer por parte de la sociedad civil la recuperación de las memorias y los testimonios orales de los hombres y mujeres que vivieron la guerra; dicho proceso se relaciona con «los efectos duraderos y profundos que ha tenido la guerra civil en la vida de los españoles, incluso en los que no habían nacido aún $»^{1}$, de ahí las inquietudes de una nueva generación en la que ha resurgido el deseo de saber más sobre el papel de sus antepasados en la guerra civil y la posguerra. Otro de los motivos de esta amplia atención pública hacia las memorias de la guerra y la dictadura se relaciona con las luchas políticas que se han llevado a cabo, desde que se inició la transición a la democracia, por la construcción de diversos sentidos de ese doloroso pasado. Elisabeth Jelin haciendo referencia a las dictaduras de los países del cono sur de América, observaba que esas luchas por la representación del pasado implicaban, por parte de los diversos actores sociales, una serie de estrategias para oficializar e institucionalizar una (su) narrativa del pasado. Existe, pues, una lucha en el terreno de los usos públicos de la memoria, una "guerra de memorias», utilizando el término empleado por Helen Graham ${ }^{2}$. Esos conflictos relacionados con la memoria pública han ocurrido también en el continente europeo desde la caída del muro de Berlín en 1989. La autora hace referencia -en el caso español-a las actitudes de rechazo a la reflexión sobre el pasado reciente, a las que se ha unido el ataque al movimiento cívico de «recuperación de memorias», que se viene dando en los sectores conservadores de la sociedad espańola todavía dispuestos a aferrarse a los mitos de la guerra creados por el franquismo.

Los debates en torno a los usos públicos de la memoria han coincidido en la historiografía espańola con una mayor atención hacia el análisis de los documentos personales. La radical división entre historia y memoria que se imponía en la historia académica de la primera mitad del siglo XX se ha ido dejando de lado. De este modo, la historia como disciplina se interesa cada vez más por los diversos sentidos con que los actores sociales resignifican el pasado ${ }^{3}$.

Una forma privilegiada de acceso a la memoria individual son las historias de vida, es decir, las entrevistas realizadas a los protagonistas de la contienda años después. En ellas los recuerdos personales han sido modelados por la memoria colectiva y por el momento en el que se produjo la entrevista, como ya señaló Ronald Fraser, autor de los relatos orales pioneros y más conocidos sobre la guerra civil española. Desde la historia oral, autores como Luisa Passerini y Sandro Portelli ${ }^{4}$ han analizado las relaciones entre memoria y subjetividad en

1. Paloma Aguilar, «Evocación de la guerra y el franquismo en la política, la cultura y la sociedad españolas», en Santos Juliá (ed), Memoria de la guerra y el franquismo. Madrid, Taurus, 2006, p. 35.

2. Helen Graham, The War and Its Shadow: Spain's Civil War in Europe's Long Twentieth Century. Portland, Sussex Academic Press, 2013; Elisabeth Jelin, Los trabajos de la memoria. Madrid, Siglo XXI.

3. Ines Mudrovic, Historia, narración y memoria. Madrid, Akal, 2005.

4. Luisa Passerini, «La memoria como subjetividad e intersubjetividad en las narraciones de memoria de las mujeres», Pilar Pérez Fuentes (ed), Subjetividad, cultura material y género: 
las entrevistas orales, afirmando que «encontrar la subjetividad en la memoria es restituir al narrador su carácter pleno de sujeto capaz de tomar decisiones sobre su propia vida y formular estrategias». Sin embargo, hay claras diferencias entre el relato de vida oral y el escrito; añade Portelli que el lenguaje oral ofrece la posibilidad de revelar las emociones del narrador a través del tono, las pausas y otros elementos y en las narraciones orales, la presencia del interlocutor realizando la entrevista es mucho más significativa que en el relato escrito.

En la actualidad cada vez es mayor el número de entrevistas orales sobre la guerra y la posguerra publicadas en la web. En gran medida este hecho ha ido unido a la creación en las comunidades autónomas de diferentes Archivos Orales 5 . No obstante, la mayoría de las historias de vida realizadas no se han publicado como tales, sino con la intervención del historiador que las transcribe y analiza, por lo que no se incluyen en este ensayo centrado en las memorias personales y no en la producción historiográfica que se deriva de ellas.

Conviene destacar la importancia cualitativa y cuantitativa de las memorias escritas sobre la guerra civil ${ }^{6}$. Hace más de una década se calculaba que los relatos memoriales suponían una quinta parte de lo publicado sobre nuestra guerra hasta 19957 ; desde entonces su número ha ido creciendo, aunque no haya sido cuantificado de nuevo. Siguen publicándose memorias de los contendientes de ambos bandos y de las diferentes corrientes políticas dentro de ellos: republicanos, anarquistas, comunistas, carlistas, falangistas, etc. No por ello debe considerarse que existe un exceso de memorias escritas que pudiera ser perjudicial para construir la historia; al contrario, la importancia de analizar todos estos documentos del yo, para la reconstrucción histórica de los años de guerra, es algo reconocido por la historiografía a partir de los años noventa en el marco de la nueva historia social y cultural, que considera fundamental el punto de vista del sujeto y de la subjetividad de los actores sociales. Las obras memoriales ofrecen mucha información sobre cómo sus protagonistas vivieron la guerra, aunque a veces la veracidad de los hechos quede oscurecida por el dramatismo de la narración, más aún si ésta tiene una intencionalidad política.

Nuestro objetivo es analizar y valorar una muestra representativa de la numerosa literatura centrada en esas memorias y autobiografías que se ha producido entre los años 2006-2014. La declaración del año 2006 como «Año de la Memoria Histórica» en Espańa y la promulgación de la «Ley por la que

Diálogos con la historiografía italiana. Barcelona, Icaria, 2010, p. 115; Alessandro Portelli, La orden ya fue ejecutada. Roma, las Fosas Ardeatinas, la memoria. Madrid, FCE, 2004.

5. Véase, como ejemplos, las webs del Archivo de la Memoria Histórica de Canarias, el Archivo de la Memoria del País Vasco (AHOA) y del Archivo de Fuentes Orales para la Historia Social de Asturias (AFOHSA), Archivo Nomes e Voces de Galicia, entre otros.

6. Un primer repaso bibliográfico de las memorias de la guerra lo realicé en Pilar Domínguez, "Viejas y nuevas memorias de la guerra civil», Studia Histórica, Historia Contemporánea. La Guerra Civil. Salamanca, Universidad, vol. 32, 2014, p. 285-298.

7. Rosario Ruiz y Sergio Riesco (1999), "Veinte años de producción histórica sobre la guerra civil española (1975-1995): Una aproximación bibliométrica», en Revista española de Documentación científica, CSIC, 22, 2 1999. p. 174-194. 
se reconocen y amplían derechos y se establecen medidas en favor de quienes padecieron persecución o violencia durante la Guerra Civil y la Dictadura», de 2007, han servido para fomentar la publicación de memorias personales. En este ensayo incidiremos en los relatos memoriales novedosos, que son especialmente útiles como fuentes históricas, y en aquellos que han tenido repercusión en un público más amplio y en los medios de comunicación social. Con este criterio, dejamos de lado numerosas reediciones y las memorias de carácter literario.

Los relatos con carácter autobiográfico, las cartas, diarios, relatos, etc., han sido estudiados desde la historia de la cultura escrita, la cual acunó el término de «ego-documentos» para referirse a esos documentos personales. Entre ellos los más interesantes son los diarios la guerra civil, algunos todavía inéditos más de setenta años desde su escritura. Como señala Anna Caballés el diario puede ser considerado «una modalidad catártica de hablar en soledad» (54). En esta escritura las referencias a lo cotidiano, el clima, los hábitos, la comida son frecuentes y le dan su mayor valor para conocer cómo se desarrollaba la vida diaria en la guerra. A menudo se trata de obras no destinadas a la publicación y que han sido dadas a conocer por los descendientes de sus autores. Otro tipo de documentos más abundantes entre las últimas publicaciones son las «memorias de guerra». El término memorias era el más usado antes de que apareciera el cultismo "autobiografía» (Caballé 51) y de hecho la mayoría de los autores comentados lo han empleado para referirse a sus escritos personales. Las memorias comprenden la relación de hechos de una vida o de una etapa histórica -la guerra civil- y evocan hechos y personajes de trascendencia. Presentan vivencias y hechos que afectan no sólo al individuo que las escribe sino también a su grupo de pertenencia, de manera que sus autores contribuyen a crear la imagen de un pasado común y con ello a la formación de una memoria y una identidad colectivas. Estos escritos personales tienen como destinatario un público amplio y tratan de influir socialmente contribuyendo a la legitimación político-social de un colectivo determinado.

Este conjunto de relatos personales sobre la contienda donde caben los diarios, las memorias y las cartas permitirá ahondar en la historia social de la guerra y sus efectos más perversos, la represión y el exilio. Entre este cúmulo de "ego-documentos» queremos destacar los de los niños, niñas y mujeres que vivieron la contienda, los llamados «niños de la guerra». Pertenecen a la generación nacida en los ańos veinte e incluso treinta, que vio truncada su infancia tras la sublevación militar. Rememoran sus experiencias ya con una edad avanzada, en un periodo de la vida proclive a hacer una reflexión sobre la trayectoria personal y realizar una síntesis de lo vivido.

8. Anna Caballé, Narcisos de tinta. Málaga, Megazul, 1995, p. 54. 


\section{Memorias de los “NiÑOS Y NiÑAS DE LA GUERRA”}

Los niños que sufrieron el trauma de la guerra y el desarraigo del exilio han sido uno de los grupos más estudiados en los últimos años. Salieron de España más de 40 mil niños por la evacuación del frente norte durante la guerra'; entre mayo y junio de 1937 fueron evacuados 20 mil a Francia, Inglaterra y Rusia desde el puerto de Santurce y luego otros tantos desde Santander, Ribadesella y Gijón. Los niños y niñas que llegaron a la Unión Soviética fueron una minoría de los evacuados, 2895. Sin embargo, su impacto literario ha sido grande, pues hay un número considerable de obras escritas por los menores que llegaron al país de los soviets. Los relatos personales se vieron quizás impulsados por la larga duración de su exilio y las penalidades que vivieron durante la Segunda Guerra Mundial; las difíciles circunstancias de su regreso a España estimularon también esas narrativas. El sólido trabajo de Verónica Sierra sobre los menores en Rusia se basa en gran parte en algunos retazos de esas memorias personales, como son las cartas enviadas por los niños a sus padres cuando llegaron a la Unión Soviética, una correspondencia epistolar que no llegó a su destino y que los franquistas depositaron en el Archivo de la Guerra Civil, origen del actual Centro Documental de la Memoria Histórica. Las memorias de la infancia también se han utilizado como fuente para el conocimiento de ese exilio y sus implicaciones políticas.

Para lograr la publicación de esas obras ha sido clave el esfuerzo realizado por algunas instituciones públicas de sus lugares de procedencia, en especial de Asturias y el País Vasco. Su propósito era «rescatar del olvido a las víctimas del golpe de estado del 36 y en especial a los nińos de la guerra que de allí salieron» en el marco de las políticas relacionadas con la aplicación de la Ley de la Memoria Histórica. Este objetivo incluyó la localización de los más de cien «nińos» que vivían en Asturias en 2011 y además la realización de un monumento de homenaje en la playa de Gijón a los menores que salieron de allí al exilio en 1937, una forma de representar su memoria en el espacio público.

Los «niños» que regresaron a España desde la Unión Soviética durante el franquismo o ya en democracia, también han sido sujetos activos en la reivindicación de su memoria y de una peculiar identidad exiliada. Crearon la Asociación de Niños de la Guerra; así el grupo se conformaba como una comunidad de memoria, basada en sus experiencias comunes y en las conmemoraciones que mantienen viva su identidad colectiva. Veremos cómo a menudo sus memorias adoptan el plural como forma narrativa, lo cual subraya la idea de que están rememorando una experiencia a la vez individual

9. Las cifras del exilio infantil las proporciona Jesús Carballés, «Los "niños de la guerra” o las huellas del exilio infantil de la Guerra Civil en el espacio público», Historia Social, «Los Niños de la Guerra», nº 76, 2013, p. 107-124. 
y colectiva. Muchos de sus relatos autobiográficos manifiestan su intención de contar la historia del grupo familiar, de los nińos que salieron y de los padres que se quedaron en España.

Sin embargo, en algunos relatos de este colectivo encontramos un tono reivindicativo, tratando de ajustar cuentas con el pasado, muchos años después del desarrollo de los hechos, con lo cual el tiempo presente interfiere con claridad en la narración. El exilio en la URSS tuvo un evidente componente político. Verónica Sierra señalaba que los niños españoles «fueron instruidos en el estilo de vida comunista, formaron parte del movimiento pionero y al ser mayores de edad, del Partido Comunista; les hicieron creer que el futuro de España estaba en sus manos ${ }^{10}$. Y algunas memorias tratan de mostrar el fracaso de esos objetivos; eso ocurre en el relato del «niño» Julián Fernández Cruz, que lleva un título polémico, Nos jodieron la vida. Las verdades ocultas de la guerra civil española. La obra se propone, entre otras cosas, mostrar el abandono y el maltrato sufrido por los niños exiliados en la Unión Soviética por parte de los dirigentes del PCE; recurre para ello a sus recuerdos personales y a los de sus compañeros de exilio. De esta narración colectiva interesan más los breves relatos personales de otros compañeros de exilio que aparecen incluidos en el libro: Luis Lavín, Luis Fonturbe, Ángel Gutiérrez y Manuel Arce, autor a su vez de un libro de memorias. Las maestras y maestros espańoles, a menudo olvidados, que acompañaron a los niños, aparecen en una relación integrada por 48 nombres.

Entre las numerosas narraciones personales de la infancia y la juventud en el exilio ruso, de reciente aparición, encontramos Memorias de un niño en Rusia (1937-1957) de Ángel Belza, que tienen mayor interés por dar a conocer la trayectoria de un exiliado poco exitoso en la URSS, la autobiografía de «un superviviente», como él se denomina. Contamos además con los escritos de Gerardo Viana, De Carranza a Siberia y las memorias de Juan Velasco. Todos ellos parten de la guerra civil y del desgarro que les supuso el exilio en 1937, pero se detienen más en sus consecuencias, y en las vivencias de la "Gran Guerra Patria», como se llamaba en Rusia a la II Guerra Mundial.

Los relatos femeninos publicados en el siglo XXI son menos abundantes. Isabel Argentina Álvarez publicó sus Memorias de una niña de la guerra y otra «niña», Nieves Cuesta, rememora su larga estancia en Rusia en la obra Simplemente mi vida. Además, María Libertad Fernández es la autora de uno de los relatos más originales, de esta índole, publicados recientemente, las Memorias de una máquina de escribir. En el libro, la máquina de escribir se convierte en un objeto clave para la rememoración de la infancia y del exilio vivido por tres hermanos asturianos; la máquina es testigo de las guerras y los numerosos viajes que tienen que emprender por la URSS y de la vuelta a casa tras veinte años de ausencia. Este recurso literario permite a la autora dejar de lado sus sentimientos personales en momentos que tuvieron que ser emotivos,

10. Verónica Sierra, «En el país del proletariado. Cultura escrita y exilio infantil de la URSS», Historia Social, Ibidem, p. 134. 
como el reencuentro de la madre con los hijos, tras veinte años de separación y hacer un relato más fiel de sus experiencias en el país de los soviets.

En estas obras, mediante la escritura autobiográfica, los menores exiliados han tratado de reconstruir su identidad familiar y grupal; además puede decirse que su escritura ha tenido en muchos casos un efecto balsámico sobre sus autores, a la vez que esas memorias ofrecen un testimonio valioso acerca de la dura vida del exilio en Rusia. Las dificultades que el régimen franquista les impuso para regresar e integrarse de nuevo en España, tratándoles siempre de comunistas, es otro de los temas recurrentes en sus escritos. Sin embargo el largo tiempo transcurrido desde los hechos narrados y el hecho de que con frecuencia estén destinadas al círculo familiar debe ser tenido en cuenta a la hora de considerarlas como fuente histórica.

\section{GÉNERO Y MEMORIAS}

El interés de la literatura femenina sobre la guerra radica en que muestra vivencias personales de mujeres que tradicionalmente habían tenido una experiencia social distinta a la masculina. Se trata de escrituras al margen de las convenciones del momento, ya que -quitando contadas excepciones- las mujeres no se ocupaban de los asuntos políticos, dada la división por género entre lo público y masculino y lo privado identificado con lo femenino. Las obras autobiográficas pioneras de las activistas políticas de la zona republicana fueron publicadas desde los primeros años de la salida del país. El trauma del exilio, vivido como un "segundo tiempo de guerra», según la acertada expresión de Mónica Jato ${ }^{11}$, ha dado lugar a numerosos relatos autobiográficos femeninos. Uno de los primeros fue el de Constancia de la Mora In Place of Splendor. The Autobiography of a Spanish Woman, escrita originariamente en inglés en 1939, cuando Constancia se encontraba en Estados Unidos ${ }^{12}$. Otros relatos memoriales femeninos, como el de Isabel de Palencia I must have liberty (1940) y Smouldering Freedom (1946), fueron también publicados en inglés con objeto de difundir y favorecer la causa de los republicanos en el exilio.

Escritos con urgencia al final de la contienda aparecen otros relatos personales, como el Diario de una refugiada española de la joven escritora Silvia Mistral, publicado en México y reeditado en España con un estudio introductorio de José Colmeiro. Cecilia Guilarte era otra joven periodista que llegó al exilio, también autodidacta y de procedencia obrera; así lo indica Mónica Jato en su interesante edición de los artículos autobiográficos de la escritora vasca. El paralelismo del origen social de ambas exiliadas, Silvia Mistral y Cecilia Guilarte, y su relación con el movimiento libertario se ponen de relieve en el estudio de

11. Mónica Jato (ed), Diario de un retorno a dos voces, Sevilla, Ulises, 2015.

12. Constancia de la Mora, In Place of Splendor. The Autobiography of a Spanish Woman. New York, Harcourt, 1939 y Doble esplendor. Autobiografía de una mujer española, México, Atlante, 1944 y Madrid, 2004. Sobre esta obra ver Pilar Domínguez, «Dos escritos autobiográficos de mujeres exiliadas en México", Revista de Indias, 2012, p. 799-824. 
la correspondencia que mantuvieron ambas a uno y otro lado del Atlántico. Ya en democracia algunas mujeres republicanas se animaron a escribir y publicar sus memorias, a menudo después de haber contado parte de sus vivencias en entrevistas de carácter autobiográfico que forman parte de archivos orales ${ }^{13}$. Del colectivo del exilio en México aparecieron las de la militante socialista Aurora Arnaiz, Retrato hablado de Luisa Julián y el libro de Carmen Parga, titulado expresivamente Antes que sea tarde ${ }^{14}$, que ha sido reeditado en México. Estas obras nos dan idea de la importancia que concedían las exiliadas a contar sus vivencias como una forma de transmitir sus experiencias políticas a las nuevas generaciones de su país.

Han aparecido algunos diarios breves de gran interés para conocer las vivencias de algunas mujeres víctimas directas o indirectas de la represión franquista que se desató al final mismo de la guerra. Uno de ellos pertenece a la maestra normalista Enma Martínez Bay, casada con el diputado Eliseo Gómez (1889-1939). Ella empezó a escribir su diario a raíz de la detención de su marido en Alicante, el 2 de abril del 39 hasta el 24 de abril del mismo año, narrando el cautiverio de Eliseo hasta que se llevó a cabo su ejecución. El, que era también profesor de la Escuela Normal de Alicante, licenciado en Derecho, concejal y diputado electo en 1936 por Izquierda Republicana, confiando en su inocencia no quiso salir al exilio. Uno de los valores principales de esta pequeña obra, editada junto a los diarios de Eliseo Bayo, es su carácter de escritura inmediata y fragmentaria, propia de un diario, que constituye un testimonio directo de la sorpresa y el dolor causado por la represión indiscriminada tras la victoria franquista. El relato diario no se estructura a posteriori, como ocurre en las memorias largamente elaboradas, lo cual le da un mayor valor documental como fuente histórica para el análisis del trauma de la guerra civil desde la subjetividad.

Asunción Amilibia, exiliada vasca, es la autora del Diario de la Nostalgia, unas memorias mucho más elaboradas, pues se escribieron años después de su salida del País Vasco, desde su exilio en Chile. Como ocurre en otras memorias femeninas, los recuerdos de una familia disgregada por la guerra ocupan gran parte de la obra y están dirigidos también a las nuevas generaciones. Su interés radica en mostrar los antecedentes del exilio español en Chile, mucho menos estudiado que el mexicano o argentino.

En el siglo XXI se han reeditado algunas memorias de mujeres publicadas antes fuera de España. Entre ellas destacamos los relatos personales de Lola Iturbe y Alejandra Soler, mujeres representativas de dos culturas políticas muy diversas, la comunista y la anarcosindicalista.

13. Las entrevistas se encuentran en el Centro Documental de la Memoria Histórica de Salamanca.

14. Carmen Parga, Antes que sea tarde. México, Ed. Porrua, 2007. La primera edición es de 1996, Madrid, Compañía Literaria, 1996; Aurora Arnaiz, Retrato hablado de Luisa Julián, Madrid, Compañía Literaria, 1996. 
El libro Vida e ideal de una luchadora anarquista recoge escritos personales y políticos de Lola Iturbe, más conocida por su obra La mujer en la lucha social y en la Guerra de España, editada en 1974 desde el exilio en Francia. Antonia Fontanilla y Sonya Torres, editoras del libro, se han esforzado por recopilar lo publicado por la autora en Espańa y en Francia. Lo más interesante entre los escritos recogidos es un breve relato autobiográfico de sesenta páginas en el que resume su trayectoria de infancia y juventud. Son unas memorias fragmentarias, pues una parte de ellas fue escrita a su regreso a España (1965) y otra en 1984 y 1985. La autora rememora su origen humilde, las penalidades de su infancia y los ańos de juventud. Su relato personal ejemplifica el profundo cambio que fue experimentando un sector de la población femenina en la Espańa urbana de las primeras décadas del siglo XX. Partiendo del papel doméstico que la sociedad les tenía reservado, numerosas jóvenes se vieron cada vez más implicadas en la actividad política y sindical antes reservada a los hombres. Lola Iturbe narra su trayectoria personal, de simple costurera en Poble Nou hasta llegar a ser una conocida militante anarquista que ejerció como reportera durante la guerra.

Las memorias de Alejandra Soler, nacida en Valencia en 1913, destacan por narrar sus vivencias de la guerra desde la perspectiva de una superviviente, ya centenaria, del conflicto bélico y del exilio. El libro La vida es un río caudaloso con peligrosos rápidos es un relato de madurez hecho, en palabras de Alejandra Soler, «al cabo de mis andanzas por la vida», una autobiografía que como tal recorre de forma cronológica su larga vida, desde la infancia y juventud, el exilio en la Unión Soviética hasta 1971 y su repatriación y vida en Valencia. El relato del largo exilio en el país de los soviets, adonde llegó para ejercer como maestra de un grupo de «niños de la guerra» allí refugiados, es la parte principal de esta pequeña autobiografía; de ella destacan las vívidas anécdotas de la guerra mundial. Su escritura, tan distanciada en el tiempo de las vivencias y los sucesos que narra, hace que se centre más en las emociones y los sentimientos sobre aquellos años, que en los hechos en sí. El relato sobre la guerra y sus dolorosas consecuencias aporta su propia valoración de la implicación en la contienda de una mujer que podemos considerar «moderna», educada por su padre en el republicanismo y el ateísmo, con estudios universitarios, y miembro del Partido Comunista.

Las escasas obras autobiográficas de las mujeres que militaron en el territorio sublevado no se han vuelto a publicar en estos años, por ejemplo las memorias de figuras tan prominentes del régimen como Pilar Primo de Rivera, editadas en 1983. Esto es una muestra del poco interés que suscitan en el público lector actual los "grandes actores» del franquismo, entre ellos la fundadora de la Sección Femenina de Falange. Ello pese a que esta institución fue -junto a la iglesia católica- la principal mantenedora del modelo de género tradicional de subordinación de la mujer al hombre durante ese período. Sin embargo, contamos con una obra escrita por una de las primeras militantes de Falange, las Memorias de la abogada Mercedes Fórmica que abarcan el período republicano, la guerra civil y la primera década del franquismo. Se hacen en ella referencias al crecimiento de la Falange entre los universitarios madrileños en los años treinta, 
pues Mercedes participó en el primer Consejo Nacional del SEU (Sindicato de Estudiantes Universitarios), a la fundación de Sección Femenina y sus tareas a lo largo de la guerra civil. Los acontecimientos narrados tienen bastante interés por ser la autora una mujer excepcional en la Falange, aunque en estas memorias los hechos se narran dentro de una construcción literaria, con tintes novelescos. La obra se escribió mucho tiempo después de los hechos, en 1982; entonces la autora mostraba un considerable espíritu crítico con respecto al régimen franquista y a la conversión de la Falange en partido oficial, lejos de los «auténticos jose-antonianos» con los que se identificaba.

\section{ACTORES DE LA ZONA REPUBLICANA Y LA SUBLEVADA}

Hay que agradecer la labor de Ángel Viñas como editor de memorias de protagonistas tan diversos de la guerra civil como el artillero republicano Antonio Cordón, de Pablo Azcárate, embajador en Londres durante la contienda y las de Francisco Serrat Bonastre, diplomático franquista. En esa última edición de memorias Viñas señalaba que la literatura testimonial pro-franquista era escasa, en comparación con la generada por los leales a la República, quizás -añado- porque la historiografía y la literatura generada por los partidarios de la dictadura ya se encargaron durante cuarenta años de hacer pública y obligatoria una versión de lo ocurrido durante la contienda; todo ello ha servido para mantener vivos algunos de sus mitos y símbolos.

De todas maneras, al calor del debate sobre la recuperación de la memoria histórica, han aparecido algunas memorias de militares del bando rebelde que actualizan esos mitos de la guerra heredados del franquismo, en un intento de rehabilitar moral e intelectualmente a los sublevados que hicieron posible la dictadura ${ }^{15}$. Algunas de ellas han visto la luz con el pretendido fin de ofrecer nuevos datos sobre la guerra; sus editores han aprovechado la ocasión para reivindicar la honestidad de algunos militares rebeldes y desmarcarlos del proyecto dictatorial del franquismo, que se presenta como una creación personal del Generalísimo y su entorno. Franco se habría así encumbrado sobre los demás altos mandos de la rebelión.

Un ejemplo de ello es la obra de B. Felipe Maíz, Mola frente a Franco, escrita poco antes de la muerte de su autor, por el que fue hombre de confianza del general Emilio Mola y su enlace civil secreto en la contienda. La obra se encontraba desde entonces en el archivo privado de Teresa Maíz, esperando el momento oportuno para su publicación. La actuación del general golpista durante la sublevación en Navarra, en la versión de Maíz, ha sido refutada por publicaciones recientes, que destacan la crueldad del general Mola y su responsabilidad directa en la violenta represión que tuvo lugar en toda la zona norte cuando estuvo bajo su mando. Estas obras de carácter hagiográfico no 
tienen apenas valor documental; su interés es más político que histórico, por las referencias a la actualidad política de sus editores.

Sin embargo las memorias de guerra de Francisco Serrat Bonastre, que forman parte de la colección de volúmenes de memorias que conserva su nieto Juan Serrat, son muy valiosas como fuente documental. Al no estar destinadas a su publicación, no persiguen dejar su huella en la historia ni defender su comportamiento del pasado, a decir de su editor; según éste las memorias de este diplomático de derechas y anticomunista «constituyen un testimonio de primera mano sobre la atmósfera creada por los hermanos Franco en la cual se gestó la política exterior del nuevo régimen». En concreto detalla el ambiente político en el gobierno de Burgos y luego en Salamanca con el "generalísimo», donde se trasluce su «desconfianza en las dotes políticas de un gobierno militar» (Serrat, 43). Su condición de cesado por Franco -en 1937- permitió a Serrat hacer un relato desmitificador de Franco y su entorno político, muy lejos de la hagiografía propia de la propaganda del régimen (Viñas 23). La obra, minuciosamente comentada por el editor, se cierra con un esclarecedor estudio dedicado a la "Carrera y tribulaciones de Francisco Serrat», donde queda explicada su trayectoria como diplomático y el contexto de su actuación, un elemento imprescindible para analizar las memorias personales, que a menudo no se encuentra en las ediciones de las autobiografías.

Respecto al territorio republicano, los militares fueron uno de los colectivos más prolíficos en la escritura memorial, desde los «grandes actores» a los soldados de a pie. El interés por la historia de la gente común ha llevado a rescatar los escritos de los combatientes. Uno de estos protagonistas era Cándido Sáez de Viana, con una obra escrita en los años finales de la dictadura. Desde esa perspectiva temporal, el autor resalta cómo la guerra transformó su vida y la de su generación, las consecuencias personales del conflicto, «marcados por recuerdos, complejos y taras físicas para el resto de nuestras vidas. El horror, el odio y el resentimiento nos acompañarán siempre como un lastre pesado e inseparable». (237). El pesimismo provocado por la larga duración de la dictadura impregna sus recuerdos de la guerra.

A veces los relatos muestran una visión de la guerra que desmitifica a los combatientes del bando republicano, que no sólo luchaban por unas ideas sino por su propia supervivencia, acercándose a los planteamientos de James Matthews sobre el reclutamiento forzoso en la guerra civil y la experiencia bélica cotidiana ${ }^{16}$. Tal es el caso de la obra de Ferrán Planes El desbarajuste; en ella el que fue teniente de artillería republicano rememora su experiencia de la guerra, sus preocupaciones por la subsistencia cotidiana, la comida, su familia, con una prosa sencilla, plagada de anécdotas. Los pasajes en que narra la derrota, el miedo ante el futuro incierto de los vencidos y la violencia que se desató contra ellos por parte de los vencedores, son muy interesantes por su carácter desmitificador de la experiencia bélica.

16. James Matthews, Soldados a la fuerza. Reclutamiento obligatorio durante la guerra civil, 1936-1939, Madrid, Alianza, 2013. 
En muchos de esos relatos aparece de forma explícita la pretensión de veracidad inherente a la autobiografía. "Todo lo que aquí está escrito son hechos verídicos, que no he tratado de aumentar ni disminuir» (41), decía otro militar, Salvador Jordá Agulló. Sin embargo, los propios autores resaltan el carácter traumático de ese proceso de rememoración, lo cual supone un alto grado de subjetividad en su escritura. Otras memorias de combatientes de reciente publicación son los Apuntes de la Historia del IV Cuerpo de Ejército, una crónica de la guerra en Guadalajara del escritor Juan Antonio Gaya Nuño, las del oficial de marina Victoriano Barroso y las Memorias políticas y militares de José del Barrio.

En el apartado dedicado a las memorias de los combatientes pueden incluirse también las pertenecientes a los brigadistas internacionales que lucharon con el ejército republicano. Entre los 35 mil voluntarios que llegaron a España hubo un grupo de ellos que recogieron sus experiencias de lucha en libros de memorias. Estas suponen, junto a las biografías, el porcentaje más elevado de lo publicado en torno a las Brigadas Internacionales en los últimos años ${ }^{17}$. Uno de ellos, Joe Monks, era un militante socialista que combatió en el frente de Jaén y Córdoba, entre diciembre de 1936 y junio de 1937; su libro Con los rojos en Andalucía. Memorias de un brigadista irlandés se editó por primera vez en inglés en 1985 y casi treinta años después en español. El relato se escribió a partir de las notas tomadas por el autor, poco después de su experiencia como integrante de las Brigadas Internacionales, por lo que tiene mayor verosimilitud que otros escritos posteriores. El fotógrafo Adrián Bodek, nieto del brigadista Gunter Bodek, es el autor de un original libro, Brigadas Internacionales. Memorias vivas, que reúne fotografías actuales y relatos autobiográficos en torno a la guerra, de un conjunto de supervivientes miembros de las brigadas internacionales. La memoria gráfica de uno de los conflictos bélicos más fotografiados de la primera mitad del siglo XX sería otro interesante aspecto a tratar, que excede las pretensiones de este artículo.

Los miembros del amplio colectivo de vencidos del territorio republicano que tomaron el camino del exilio han tenido también una abundante producción de memorias que se centraban en las causas inmediatas de su destierro. Muchas de las obras de los políticos más prominentes fueron editadas en Francia y México hace tiempo. Ahora se han editado algunas que provienen de refugiados españoles menos conocidos y que llegaron a los diversos lugares de la diáspora republicana, como Venezuela. Allí fue acogido el industrial Luis de Aranguren. De sus Memorias de un exiliado vasco destaca su visión del nacionalismo, desde el cambio de siglo con la monarquía, la Republica, la guerra y el exilio; tienen interés en primer lugar para la historia local, pero también para la del exilio vasco en Venezuela.

Alfredo Cabanillas, periodista y director hasta mediados de 1937 del Heraldo de Madrid y exiliado en Argentina hasta los años sesenta, escribió la Historia de

17. Manuel Requena y Lourdes Prades «Las Brigadas Internacionales» en Studia Historica... Op. cit., p. 181-195. 
mi vida, en los inicios de la transición democrática, con más de 80 ańos. Respecto a la guerra, su relato se centra en los casos en que intervino, como director del Heraldo y amigo de republicanos y socialistas, en contra de la represión de las checas de Madrid, que se llevaba a cabo hacia los sospechosos de apoyar a los sublevados, citando los nombres de aquellos a los que ayudó. El autor sostiene que sólo habla de los hechos de los que fue testigo, pero el paso de los años hace que estos se presentaran en una reconstrucción novelada, de amena lectura aunque poco fiable. Cabanillas defiende y justifica su comportamiento como católico y republicano durante el conflicto, algo que le condujo a tener que salir de España en agosto de 1937. Sus memorias dejan patente la difícil posición política de esos republicanos de clase media en el ambiente revolucionario que se vivía durante el primer año de la guerra.

Los diarios y memorias de guerra de «los grandes actores» de la política republicana han constituido una fuente histórica de primer orden para el estudio de su actuación pública y la de los gobiernos republicanos durante la contienda. La mayoría fueron editados en España durante la transición democrática; en el periodo que nos ocupa hay que señalar la aparición de las obras completas de personajes políticos tan relevantes como Manuel Azaña, Francisco Largo Caballero y Diego Martínez Barrio, que incluyen escritos autobiográficos. En la edición de las memorias del presidente de la República, Santos Juliá realiza un pormenorizado estudio introductorio del período bélico que sirve para situar mejor al personaje y su obra. Contiene la obra algunas novedades documentales, procedentes del archivo privado de su viuda Dolores Rivas Cherif, como son las conversaciones telegráficas de Azańa con Prieto y Martínez Barrio de mayo del 37, junto a algunas cartas inéditas a Cipriano Rivas Cherif. Su relato más interesante es el "Cuaderno de La Pobleta», escrito en 1937, donde Azańa escribe sus impresiones de las conversaciones con diversos personajes políticos. Posteriormente continuó su diario en Pedralbes hasta enero de 1939. En conjunto esos diarios serían -según la introducciónuna guía para unas memorias políticas y de guerra que su autor no tuvo tiempo de escribir, pero muy valiosas para construir su biografía y parte de la controvertida historia de la política republicana durante la guerra civil. Sin embargo, como hace notar Âlvarez Rey en la introducción al libro Diego Martinez Barrio: palabra de un republicano, los diarios de Azaña a veces fueron inexactos e injustos con la actuación política de Martínez Barrio, al que acusaba de no haber cumplido con sus obligaciones. Las frecuentes discrepancias entre los escritos personales indican que para los historiadores es imprescindible contrastar los testimonios entre sí y cotejarlos con otras fuentes primarias.

Los relatos personales que hemos analizado en este breve repaso bibliográfico, y en especial los diarios de guerra por su escritura inmediata, plantean al investigador el reto de afrontar la relación entre la biografía y la historia, entre la experiencia personal de la guerra y la experiencia colectiva, aspectos fundamentales para la construcción de una historia poliédrica del conflicto. 


\section{Relación bibliográfica de memorias mencionadas en el texto}

Amilibia Asunción, El diario de la nostalgia, Tafalla, Txalaparta, 2006.

Aranguren Luis de, Memorias de un exiliado vasco, Bilbao, Ayuntamiento, 2010.

Azaña Manuel, Obras completas.Manuel Azaña (Ed. Juliá Santos), Madrid, Centros de Estudios Políticos y Constitucionales, 2007, Tomo 6.

Azcárate Pablo, En defensa de la República, con Negrín en el exilio (Ed. Viñas Ángel), Barcelona, Crítica, 2010.

Barroso Victoriano, En nombre de la libertad, Madrid, Silex, 2014.

Belza Ángel, Memorias de un niño de Rusia, 1937-1957, Madrid, Paradiso, 2009.

Bodet Adrián, Brigadas Internacionales. Memorias vivas, Madrid, La Oficina, 2014.

Cabanillas Alfredo, Historia de mi vida. Memorias, Sevilla, Renacimiento, 2011.

Cordón Antonio, Trayectoria y recuerdos de un artillero (Ed. Viñas Ángel), Madrid, Espuela de Plata, 2008.

Del Barrio José, Memorias políticas y militares, Madrid, Pasado y Presente, 2013.

Fernández Cruz Julián, Nos jodieron la vida. Las verdades ocultas de la guerra civil española, Oviedo, Camelot, 2014.

Fernández María Libertad, Memorias de una máquina de escribir, Gijón, Ayuntamiento, 2011.

Fórmica Mercedes, Memorias (1931-1947), Sevilla, Renacimiento, 2013.

Gaya Nuño Juan Antonio, Apuntes de la Historia del IV Cuerpo Ejército. Guadalajara (1936-1939), Madrid, Cálamo, 2015.

Gómez Eliseo, Diarios de la guerra civil (1936-1939), (edición de Bustos Beatriz y Moreno Francisco), Alicante, Archivo de la Democracia, 2008.

Guilarte Cecilia, Un barco cargado de... (Ed. Jato Mónica), Sevilla, Renacimiento, 2012.

Jordá Salvador, Mis memorias de la guerra civil española (1936-1939), Alcoi, AEHA, 2010.

Maíz B. Felipe, Mola frente a Franco, Pamplona, Laoconte, 2007.

Martínez Barrio Diego, Diego Martínez Barrio: palabra de un republicano (Ed. Álvarez Rey Leandro), Sevilla, Ayuntamiento, 2007.

Mistral Silvia, Exodo. Diario de una refugiada española (Ed.Colmeiro José), Barcelona, Icaria, 2009. 
Neves Mario, La matanza de Badajoz, crónica de un testigo, Badajoz, Ed. Regional de Extremadura, 2007.

Oyarzábal Isabel, Rescoldos de libertad. Guerra civil y exilio en México, Málaga, Alfama, 2009.

Planes Ferrán, El desbarajuste, Barcelona, Libros del Asteroide, 2013.

Torres Sonia y Fontanella Antonia, Lola Iturbe. Vida e ideal de una luchadora anarquista, Virus, 2006. Accesible on line: www.viruseditorial.net/pdf/LIturbe.pdf (consultado en octubre de 2014).

Velasco Juan, Memorias de un niño de la guerra civil española, Bilbao, Delia, 2009.

Viana Gerardo, De Carranza a Siberia... y más allá, Carranza, Ayuntamiento, 2008.

Viñas Ángel (ed.), En el combate por la Historia, Barcelona, Crítica, 2012.

- Salamanca 1936. Memorias de Francisco Serrat Bonastre, Barcelona, Crítica, 2014. 
